I.A. Sloan MD FFARCS(ENG) FRCP(C) FAAP, Nancy K. Ironside MD FRCP(C)

\title{
Internal mis-mating of breathing system components
}

A patient anaesthetized for bronchoscopy could not be ventilated when components of the breathing system met too closely and preverted the out flow of expired gas. This type of obstruction within the system may occur in the Ayre's T-piece, and when "low dead space" mask angles or co-arial systems are used with "low dead space" tracheal connectors or bronchoscopes. The problem is especially dangerous because it is not easily identified and subjects the patient to a very high airway pressure.

\section{Key words}

COMPLICATIONS: accidents, hazards; EQUIPMENT, CIRCuITs: Ayre's T-piece, co-axial; tracheal tube connector.

For some time, anaesthetists have known that the fresh gas inlet to the Ayre's T-piece can become occluded within the $T$-piece. If the female end of the T-piece is slightly oversized (or the mating male fitting slightly undersized), the male connector may enter too far into the T-piece and block the inlet. To overcome this problem, some manufacturers have projected the fresh gas inlet tube into the T-piece. Although the male component may then "bottom" or not engage securely, blockage is prevented. Increasing the length of the female end of the T-piece also prevents occlusion.

In September, 1983, a safety alert issued by the United Srates Food and Drug Administration'

From the Department of Anaesthesia, University of Toronto and The Hospital for Sick Children, Toronto, Ontario and the Department of Anaesthesia, Orillia Soldiers' Memorial Hospital, Orillia, Ontario. Address correspondence to: Dr. I.A. Sloan, Department of Anaesthesia, The Hospital for Sick Children, 555 University Avenue, Toronto, Ontario, Canada M5G IX8. cautioned that "low dead space" breathing circuit components, for example, the Nesi mask-angle ${ }^{2}$ (also known as the Cape Town, Cardiff, Liverpool, Norman, NRPR, Keets-Hanks-Rackow elbows), or Rendell-Baker triple-swivel, and some co-axial breathing systems, may incorporate a fresh gas inlet tube which may protrude into or near the end attached to the tracheal tube connector (Figure 1). If

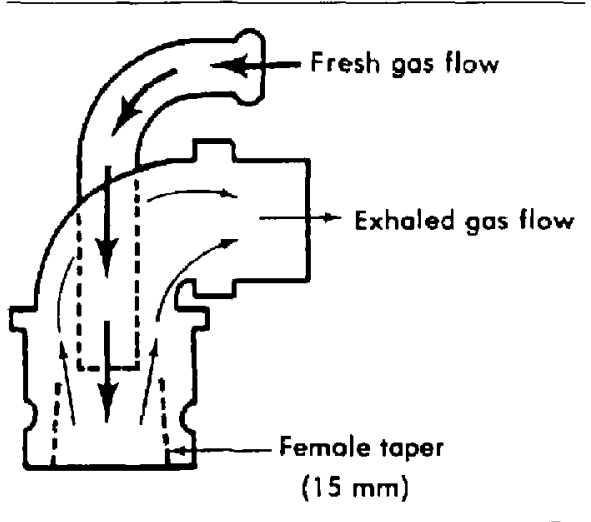

FIGURE 1 "Low dcad space" mask angle with co-axial fresh gas inlet tube (Nesi type).

these components are used in combination with a "low dead space" tracheal tube connector (Figure 2) (Cook Inc., PO Box 489, Bloomington, IN, 47402) or similar component (e.g., the ACMI fibre-optic bronchoscope) (American Cystoscope Makers Incorporated, 8 Pelham Parkway, Pelham Manor, Pelham, N.Y. 10803), the fresh gas inlet tube may closely approach or press against the male connector, causing an internal mis-connection (Figure 3).

\section{Case report}

A 78-year-old malc was uneventfully anaesthetized for bronchoscopy with a rigid bronchoscope in a 


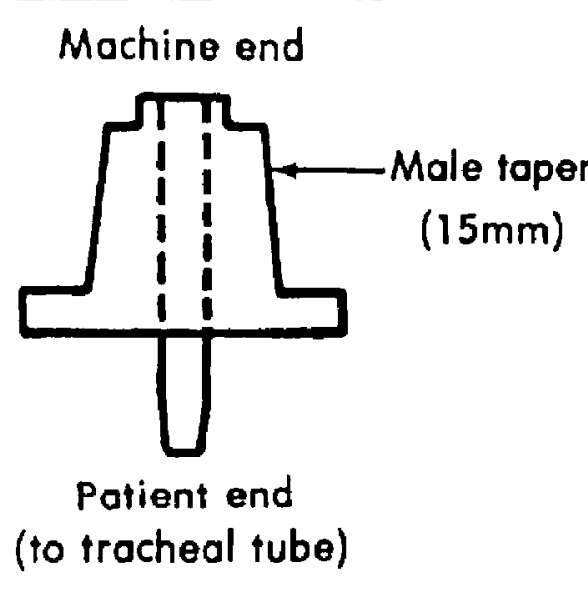

FIGURE 2 "Low dead space" tracheal tube connector (machinc and opening may be small as $3 \mathrm{~mm}$ ).

community hospital. An ACMI fibre optic bronchoscope was then passed and connected to the Penlon( co-axial breathing circuit (Penlon Lid., Abingdon, Oxfordshire, England). The reservoir bag emptied but did not refill, and the patient could not be ventilated. When an oxygen flush did not fill the bag, the bronchoscope was removed and the

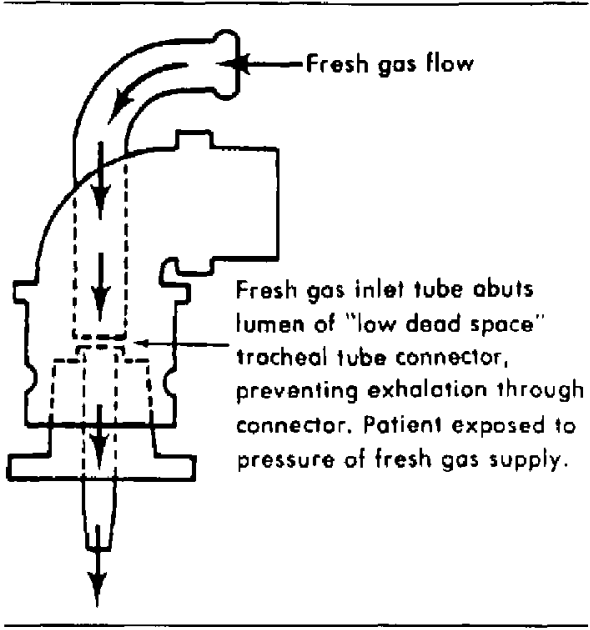

FIGURE 3 Hazard which may result when an incompatible "low dead space" mask angle is used with a "low dead space" tracheal tube connector which may "bottom" and abut the fresh gas inlet tube.

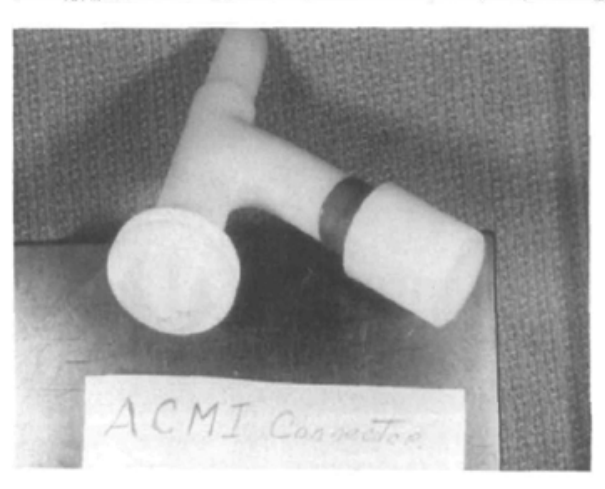

FIGURE 4 Connector used wilh ACMI fibre-optic broncluscope.

patient was ventilated easily by face mlask. The fibre optic bronchoscope was then re-inserted but again the patient could not be ventilated and inspection showed occlusion of the breathing system. This resulted in continued hyper-inflation of the lungs by the fresh gas flow, greatly exacerbated when the oxygen-flush device was used. Exhalations were blocked by the internal mis-connection of the bronchoscope to the fresh gas inflow. The connector used is seen in Figure 4. The circuit was replaced and the small bilateral pneumothoraxes were drained. The patient recovered uneventfully.

\section{Discussion}

The problem of gas flow pathway occlusion has become apparent recently with the increasing interest in reducing dead space and the use of plastic components which may vary in size or shrink with age, and allow deeper engagement than metal fittings. As the components are opaque, visual inspection is impossible. Furthermore, these components are not usually connected for a preoperative check.

Obstructions may be prevented by using only one "low dead space" device at a time, or by removing one set of components from scrvice so that mismating is unlikely (Figure 5).

As further occurrences of gas flow pathway occlusion are likely, anaesthetists should be alert to the possibility of an internal misconnection, especially when using co-axial systems or low dead space or plastic components. 


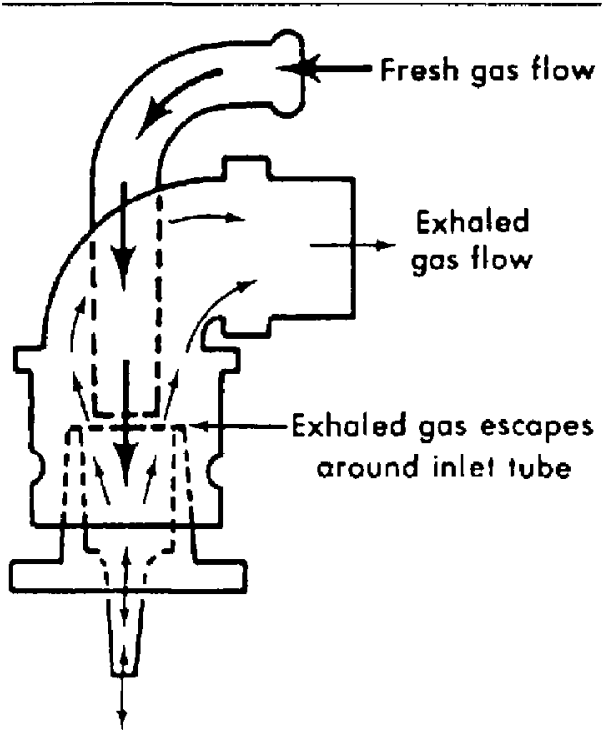

FIGURE 5 Typical gas flow will slandard tracheal tube connector (machine end opening at least $11 \mathrm{~mm}$ ). Conical end of connector allows gases to escape around the fresh gas inlet.

\section{Acknowledgement}

This paper was prepared with the assistance of the Medical Publications Department, Hospital for Sick Children, Toronto. Figures 1-3, and 5 were reproduced with the permission of the Center for Devices and Radiological Health, Food and Drug Administration, Public Health Service, U.S. Department of Health and Human Services, Rockville, Md., U.S.A.

\section{References}

1 Villforth JC. FDA Safety Alert: Breathing System Connectors. Food and Dug Administration, Rockville, MD, USA 20857. 2 September, 1983.

2 Nesi FJ. Adaptation of Ayre's T-piece to a small mask. Br J Anaesth 1951; 23: 198.

\section{Résumé}

Au cours de l'anesthésie d'un patient pour bronchoscopie, la ventilation est devenue impossible lorsque les pièces du circuit d'anesthésie ont été articulées ensemble; celles-ci à cause de disproportion de leurs diamètres respectifs, s'interpénétraient de façon excessive et empéchaient la sortie des gaz inspirés. Ce type d" obstrucrion peut survenir:

$I$ dans le montage de la pièce en $T$ de Ayre,

2 lorsqu'un masque despace mort minime se coude,

3 lorsque des connecteurs trachéaux à fable espace mort sont raccordés à un système co-axial ou un bronchoscope.

Ces incidents sont particulièrement dangereux cas on n'en identifie pas la source aisément et les voies aériennes peuvent être soumises à des pressions très élevées. 